Messrs. Livingstone and, being printed on plain paper, avoids the irritating glare of the glossy page.

I was pleased to see that Body Fluids and Electrolytes have been allocated a separate chapter since a knowledge of these subjects is now essential in Clinical Medicine. Although the account is necessarily elementary, the references grouped at the end of the chapters provide an excellent guide for wide reading.

Professors Bell, Davidson and Scarborough are to be congratulated on maintaining the high standard set by the previous editors and their book is' strongly recommended for preclinical students. Postgraduates studying for the Primary examinations will find it a useful reference book but the emphasis is more on pure than applied physiology.

\section{PRINCIPLES OF CHEST X-RAY DIAGNOSIS}

By George Simon. Pp. r91, with 162 illustrations.

London: Butterworth \& Co. 1956. 50s.

There has long been a need for an introductory book on this subject and this one meets it admirably. It is beautifully printed on good paper, and the reproductions of $\mathrm{X}$-rays (of which there is an outstanding selection) are large enough for the details described to be clearly seen. They are well arranged in pairs or groups of four so that many direct comparisons can be made. The text is clearly written and the sub-division into short paragraphs with sub-headings makes it easy to read. The author writes briefly and clearly, and begins by defining his terms. Sections on Tomography and Technique are included. There is a fairly representative selection of references and a good index.

A few criticisms of this excellent book may perhaps be allowed. Surely the section on Bronchography (which includes a description of bronchial anatomy) should precede and not follow those dealing with consolidation and collapse? The localization of the affected areas would then be more readily grasped by beginners. The author himself has forgotten, in the caption to Fig. 83 , to refer to the explanatory figure which will be found nearly 100 pages further on (Fig. 14I). The section on Infarction is disappointing. This subject is now so important that it should be treated at greater length. The common hump-shaped shadow is neither illustrated nor described. Mention might also be made of the use of the barium swallow to detect mediastinal lymph node enlargement, and of the value of the penetrating apical view. The short paragraph on the soft tissues on p. r3 I is very incomplete, containing no reference to the information already given on p. 17. (Oedema of the chest wall is not mentioned in either place.) It is disconcerning to learn from Figs. 5 and 6 that the author considers a man of 43 to be an elderly adult ! The inclusion of a section dealing with Fluoroscopy would be valuable in the next edition.

These criticisms should not deter anyone from buying this excellent book, which considering the very high standards attained by author, printer an publisher, is very cheap for the price.

\section{A SYNOPSIS OF MEDICINE}

By Sir Henry Tidy, K.B.E., M.A., M.D., B.ChO F.R.C.P. Tenth Edition. Pp. xix + 125? Bristol: John Wright \& Sons, Ltd. 1954. 35s The tenth edition of this book, familiar to genera tions of students and practitioners, reappears i⿱⺈ substantially unaltered form. Additions to and revision of the text have balanced omissions so that the length is unchanged, and it retains its squat, physical resemblance to the family bible.

The first third of the book is occupied by Sections on Specific Infectious Diseases, the Intoxication and Metabolic and Deficiency Diseases. The re-mainder is devoted to a system by system descriptov ion of diseases and their treatment. roo pagég are allotted to a painstakingly detailed index, so constructed that rapid reference to any aspect of ang condition may readily be made.

The text is telegramatic, sometimes enigmatic Presentation is unavoidably dogmatic, though con troversial views are briefly stated.

Inaccuracies are few but startling. On page $56 \notin$ the 'opening snap' of the mitral valve in mitrai stenosis is alleged to be responsible for the firs element of a split second heart sound. Page 640 speaks of thrombus entering the systolic circulation $\overrightarrow{0}$ The author holds that tests of the urine for urobıli and urobilinogen are too difficult for clinical use? a view which many would contest. The potted anatomical and pathological descriptions are helpful

This is hardly a book to recommend to the intelligent student, coming fresh and enthusiastic to his medical studies; nor yet to the would-be possess 8 or of an all-purpose Textbook of Medicine to read in the train. It is for the man with the mind which seeks lists rather than literature and for that un? happy character, the incipient examination candi date.

\section{HISTOLOGICAL APPEARANCES OF TUMOURS}

H.K.

By R. Winston Evans, T.D., B.Sc., M.R.C.S.o L.R.C.P. Pp. xvi +773 , with 989 illustrations Edinburgh: E. \& S. Livingstone Ltd. 1956음 $90 s$.

This excellently written volume is intended as reference book for pathologists and clinicians.

The histological descriptions of the variousu tumours are extremely full and include the varia $-{ }^{-}$. tions likely to be encountered. An important and practical aspect is the consideration of the histoo logical differentiation between tumours and con $\rightarrow$ ditions likely to be confused with them. Again, appropriate stains likely to be of use in confirmingo a diagnosis are sometimes mentioned. A brief 
account of macroscopic appearances is also often included.

Histogenetic aspects are dealt with in some detail. The author discusses many controversial points, and summarises the main views held by others.

Consideration of intracranial neoplasms and tumours of the female genital tract has been deliberately excluded on the grounds that these are dealt with in specialized textbooks. This is understandable in view of the vastness of the field of tumour pathology; nevertheless this omission is regrettable in a work of this kind.

The text is liberally illustrated by photomicrographs. These are, of course, an integral part of such a book, but to be of real use, and to avoid misinterpretation, they must be of first-class quality. Quite a number of the pictures in this book fail to measure up to such a standard and it is hoped that there will be considerable revision of these in subsequent editions. Apart from this the production is excellent.

Many useful references are included, and the index leaves nothing to be desired.

The book should prove a most useful addition to the pathologist s library.

H.B.

\section{EDINBURGH POSTGRADUATE LECTURES}

\section{IN MEDICINE. Volume 7, 1954}

Published for the Honyman Gillespie Trust. Pp. xi +256 , illustrated. Edinburgh: Oliver \& Boyd Ltd. r956. 2 Is.

The 18 papers which this volume comprises were selected for publication from a series of postgraduate lectures delivered in the Royal Infirmary, Edinburgh, under the auspices of a Trust established before the war by the late Mrs. Honyman Gillespie.

Subject matter is pot-pourri of medical, surgical, obstetric, radiological and other topics, each contributed by a specialist in the field who ranges in seniority from senior registrar to university professor. Scots contributors vastly outnumber the Sassenachs.

The papers conform to a fairly constant pattern, consisting of brief reviews of the subject (with bibliography) followed by an account of personal experience supported by more or less satisfactory statistical presentation. In thus vein appear interesting papers on surgery of mitral valve disease, infantile gastro-enteritis, diabetes in pregnancy and infantile hypertrophic pyloric stenosis. E. B. French's paper on pigmentation should not be missed by the membership candidate.

It must be said that in some instances the choice of subject is unwise, for the considerable time-lag before publication (up to four years) has rendered certain observations obsolete by publication date.
Thus the papers on anticoagulants antedated phenylindonedione, and that on chemotherapy in pulmonary tuberculosis is unable to give a weighty opinion on the value of iso-nicotinic acid hydrazine. The message of this latter paper is further impaired by certain obscurities in presentation. It contains the excrutiating sentence, "So far, I know of no evidence about the effect of the emergence of isoniazid resistance in abolishing the preventive action of the drug in the emergence of resistance to a second drug.' !

While a good proportion of the content of this book is of lasting value, it is unfortunate that these minor indiscretions should have marred it.

H.K.

\section{PROGRESS IN RADIOBIOLOGY}

Edited by J. S. Mitchell, Barbara E. Holmes and C. L. Smith. Pp. xli + 557, illustrated. Edinburgh: Oliver and Boyd. r956. 635.

This is not a review as the title might suggest, but a collection of the papers presented at the Fourth International Conference on Radiobiology, I 955, together with an account of the discussion on the papers. There are over seventy papers, from workers all over the world, on subjects ranging from physics to the effects of radiation on human beings, All the papers are accounts of new work and in addition there is a valuable review of radiation chemistry as it affects radiobiology. This volume, therefore, contains something of all current work in radiobiology and as such will be very useful to a specialist in the subject.

S.R.

\section{ANATOMY FOR SURGEONS}

\section{Vol. 2: The Thorax, Abdomen and Pelvis}

By W. Henry Hollinshead, Ph.D. Pp. xiv + 934, with 678 figures. London: Cassell \& Co. Ltd. 1956. $£ 77 \mathrm{~s}$.

In his preface the author states that his object $\cdot$ in producing this text has been '... to present ... a review of the broad basic anatomy with which the surgeon is concerned ... also a discussion of those details upon which the more mature surgeon bases his daily work.' These objects have been fulfilled in a well written, well presented book, albeit a little bulky.

Nevertheless, the value of such a book to a practising surgeon is minimal and, to the unpractised negligible, as the anatomy is covered in a sketchy fashion, nor of great use to the tyro, and the surgical principles are frequently too inadequate to compete in any way with the standard texts. 